\title{
Philanthropy \\ and COVID-19
}

Measuring one year of giving

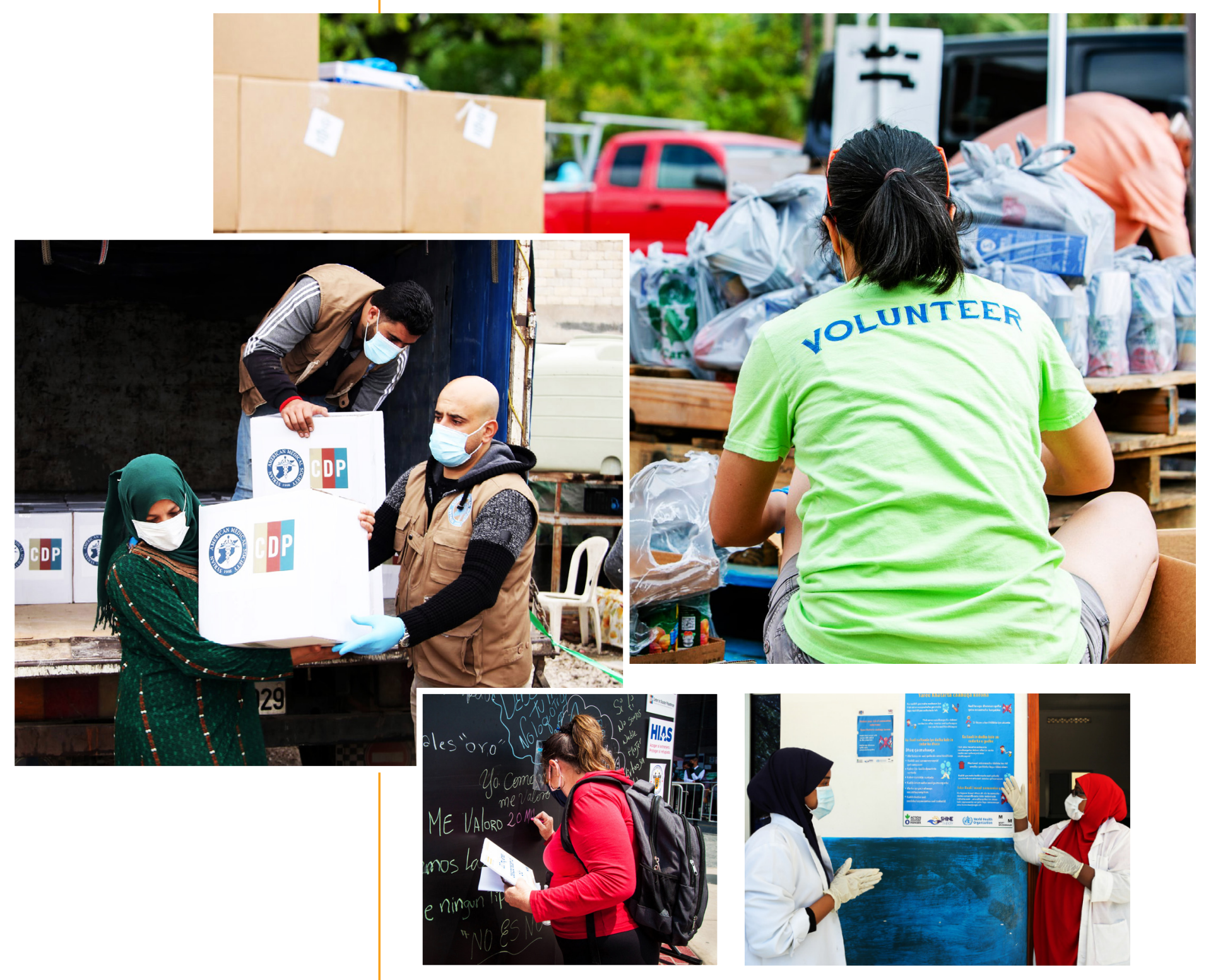




\section{Contributors}

\section{Candid}

Grace Sato

Director of Research

Supriya Kumar

Global Partnerships Research Manager

Guy Mika

Research Assistant

Suzanne Coffman

Editorial Director

Betty Saronson

Senior Visual Designer

Andrew Grabois

Corporate Philanthropy Manager

Matthew Ross

Data Discovery Manager

Katherine Neiheisel

Electronic Reporting Liaison

Naomi Henry-Salami

Data Discovery Analyst

Adia Colar

Communications and Outreach Manager

Laia Griñó

Director of Data Discovery

\section{Center for Disaster Philanthropy}

Regine Webster

Vice President

Tanya Gulliver-Garcia

Director of Learning and Partnerships

Kristina Moore

Director of Marketing and Communications

Ruja Entcheva

Marketing and Communications Manager

\section{About Candid}

Every year, millions of nonprofits spend trillions of dollars around the world. Candid finds out where that money comes from, where it goes, and why it matters. Through research, collaboration, and training, Candid connects people who want to change the world to the resources they need to do it. Candid's data tools on nonprofits, foundations, and grants are the most comprehensive in the world. In February 2019, Foundation Center and GuideStar joined forces to become Candid, a 501(c)(3) nonprofit organization.

For more information, visit candid.org or tweet us @CandidDotOrg.

\section{About the Center for Disaster Philanthropy}

The Center for Disaster Philanthropy leverages the power of philanthropy to mobilize a full range of resources that strengthen the ability of communities to withstand disasters and recover equitably when they occur. It manages domestic and international disaster funds on behalf of corporations, foundations and individuals through targeted, holistic and localized grantmaking. For more information, visit disasterphilanthropy.org or tweet us @funds4disaster.

(C) 2021 Candid and the Center for Disaster Philanthropy

This work is licensed under a Creative Commons AttributionNoDerivatives 4.0 International License, creativecommons.org/licenses/by-nd/4.0.

doi.org/10/gh5dzk

\section{Cover, left to right}

Syrian American Medical Society (SAMS) distributes hygiene kits in the Beka'a Valley in Lebanon to assist refugees with personal protection and household sanitization. Photo courtesy of SAMS

A volunteer bags groceries and meals for hungry families in New Orleans. Photo courtesy of Culture Aid NOLA
Open street event sponsored by HIAS where women write messages of hope, resilience, and empowerment, as part of the 16 Days of Activism against Gender-Based Violence. Photo courtesy of HIAS

Health staff in Somalia put up informational materials at one of Action Against Hunger's Maternal and Child Health Centers. Photo courtesy of Fardosa Hussein for Action Against Hunger 


\title{
Foreword
}

\author{
By Patricia Mcllreavy, President and CEO, \\ Center for Disaster Philanthropy
}

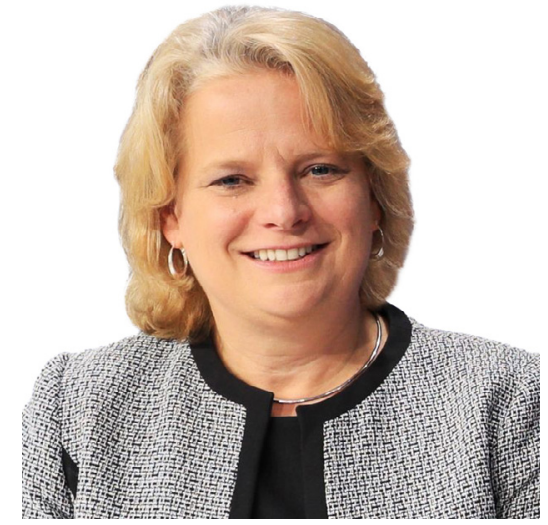

Patricia Mcllreavy
As of February 22, 2021, the coronavirus pandemic has claimed the lives of more than 2.5 million people around the world, with an additional 110 million people infected. And while data such as this serves an enormous purpose in understanding the scale and scope of a disaster, aiding experts in determining needs and directing resources, it remains far from the complete picture of the impact of COVID-19 on humanity.

The health, social, and economic impacts of COVID-19 will continue to grow as the pandemic rages. Even with vaccine roll-outs, there remains much to be done to ensure that we-as a global communityrecover from the devastation wrought on individuals, families, communities, and countries. Furthermore, we cannot separate the pandemic's repercussions from the long-overdue racial reckoning in the U.S. and other disasters occurring across the world.

The truths of this moment in time have given rise to hard conversations within philanthropy. No longer is it sufficient to fund band-aid responses to a disaster without exploring root causes-specifically, the structural inequities and systemic discrimination that result in disproportionate impacts on marginalized and underserved communities. Nor is it appropriate to pre-determine a community's needs and the necessary solutions from afar.

Philanthropy's response to the COVID-19 pandemic demonstrates that not only can donors be exceedingly generous in a crisis, but they can lead through trust and courage. In this new report, the Center for Disaster Philanthropy and Candid recognize this leadership, as demonstrated by increased overall giving, even if too little of it is in the form of unrestricted grants and funds directed toward Black, Indigenous, and other communities of color. There remains much to be done, especially regarding support for programs that deliver the policy and system changes necessary to redress generations of inequities.

Disaster philanthropy isn't simple, but trusting those closest to the crisis to provide an accurate diagnosis and guide the response is a good start. Although philanthropy's overall self-improvement journey is far from over, current efforts toward more effective practices show the way for those looking for it. 


\section{Introduction}

It has been a year since the global outbreak of COVID-19, and the world is still recovering and operating in what we have come to accept as the “new normal.” In 2020, we saw funders react swiftly, not only directing emergency funds to organizations on the ground but also committing to changes in their grantmaking practices and priorities to better help nonprofits face the myriad challenges brought on by the pandemic.

In August 2020, Candid and the Center for Disaster Philanthropy (CDP) looked at the philanthropic dollars that were distributed for COVID-19 in the first half of 2020. In the report, we found that total philanthropic funding awarded for COVID-19-related efforts during the first six months of 2020 dwarfed funding for other recent disasters. We also found that, despite many foundations' commitments to providing flexible support for grantees, few awards in the data set were specifically identified as general support. And only 5 percent of foundation and public charity funding that specified recipients was designated for Black, Indigenous, and people of color (BIPOC) communities, despite these populations being disproportionately affected by the pandemic.

A woman visiting her grandmother. Source: xavierarnau

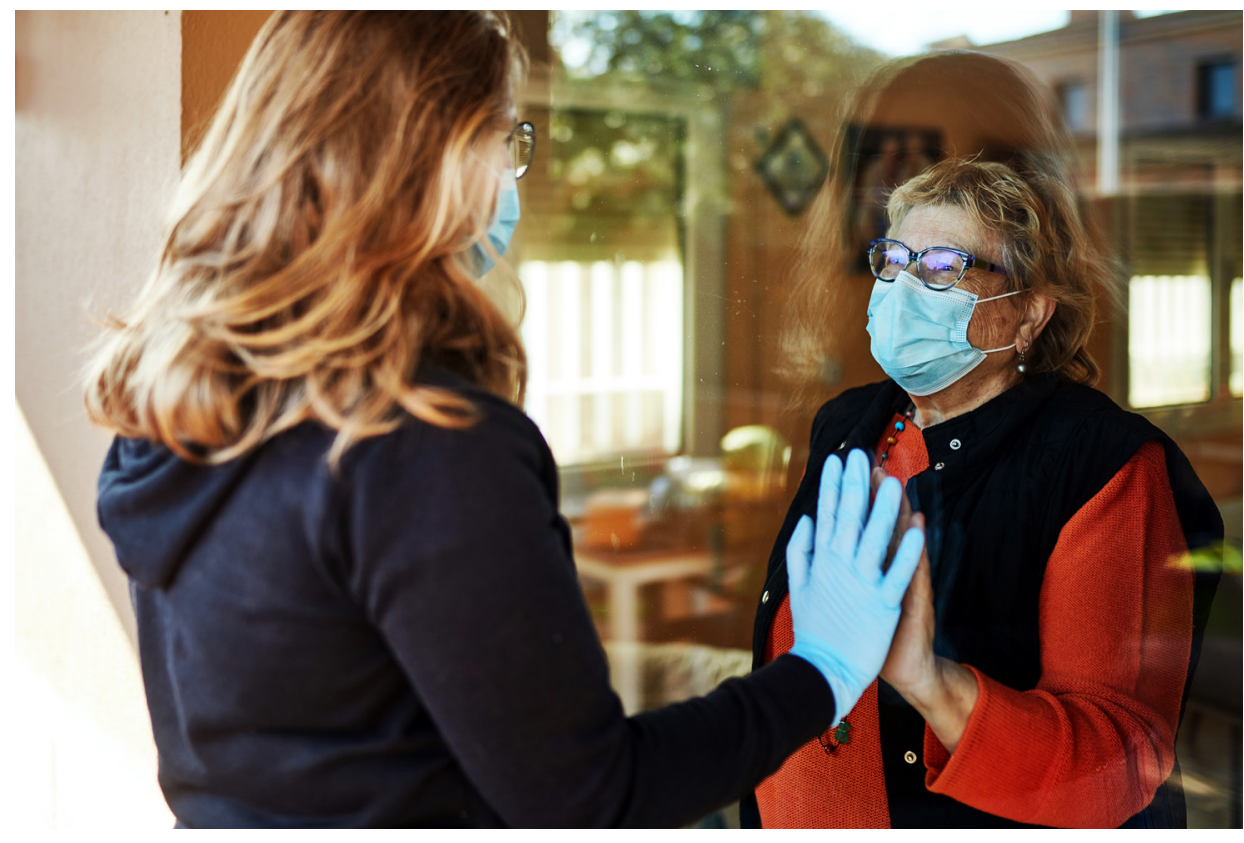


Graduation Day at North High in Des Moines, lowa. Source: Phil Roeder
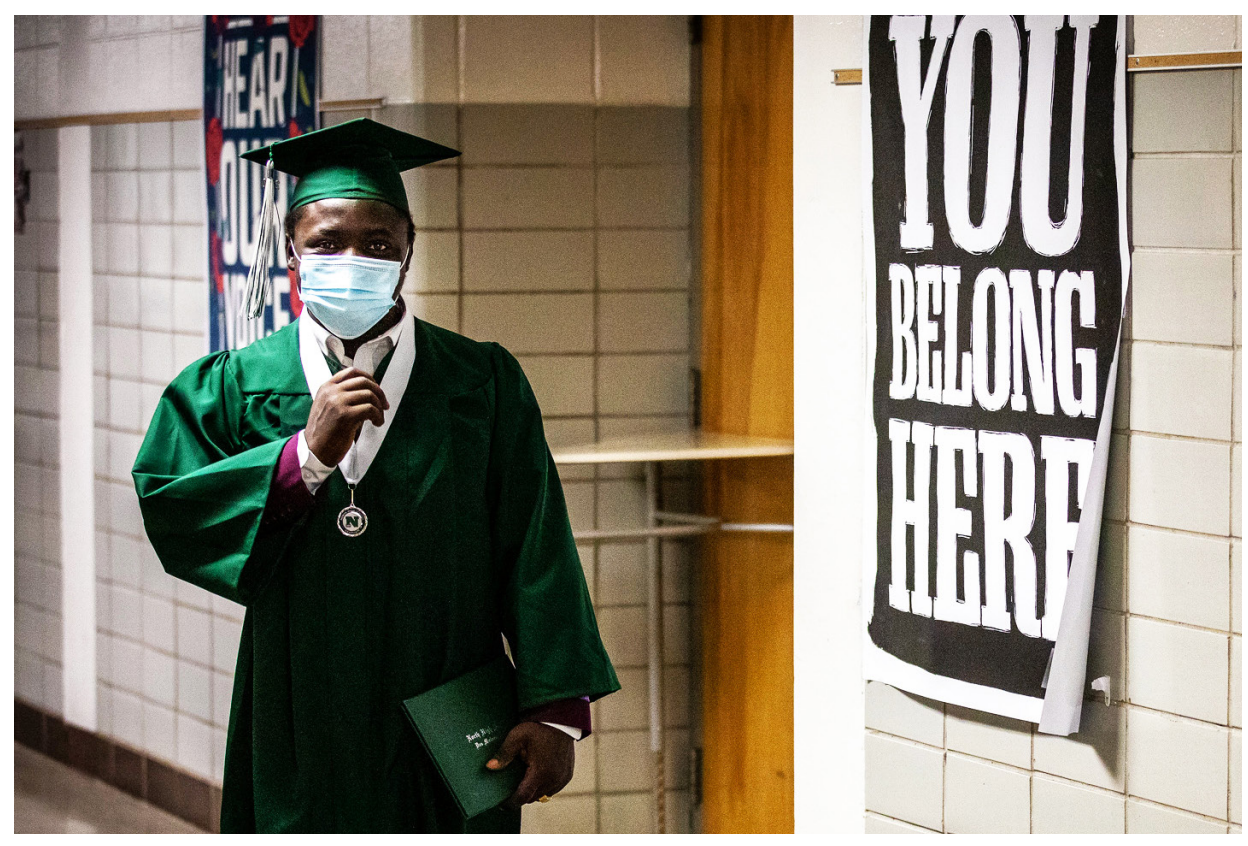

In this report, we provide an update and look at the global philanthropic response to COVID-19 in all of 2020. Some key findings:

- We identified more than $\$ 20$ billion awarded for COVID-19 globally in 2020.

- Corporations accounted for 44 percent of the funding.

- Community foundations awarded more grants than any other grantmaker type (54 percent of total awards).

- Gifts by high-net-worth individuals accounted for at least $\$ 5.8$ billion.

- An additional combined $\$ 14.6$ billion was donated through the donor-advised funds of Fidelity Charitable, Schwab Charitable, and Vanguard Charitable.

- Of U.S. COVID-19 philanthropy to specified recipients, 35 percent of dollars was explicitly designated for BIPOC communities. Because of MacKenzie Scott’s large donations, high-net-worth donors designated a higher proportion of funding for BIPOC communities than institutional philanthropy (corporations, foundations, and public charities).

The promise and delivery of the vaccines brings a light of hope after more than a year of struggle in a "once-in-a-century" pandemic. But the long-term socioeconomic and health effects will likely not subside anytime soon, even as the number of people infected by the virus starts to fall. Philanthropy will continue to be called upon to support nonprofits and non-governmental organizations (NGOs) so that they are sustainable and equipped to provide important resources. We hope this analysis assists donors as they consider how to maximize the impact of their disaster-related giving in 2021 and in the years to come. 


\section{Philanthropic funding for COVID-19}

\section{Candid tracked}

\section{$\$ 20.2$ billion}

in funding from corporations, foundations, public charities, and high-net-worth individuals to address the COVID-19 pandemic in 2020.
Candid tracked $\$ 20.2$ billion in funding from corporations, foundations, public charities, and high-net-worth individuals to address the COVID-19 pandemic in 2020-nearly double the total reached from the first half of the year. (For more about the data and methodology, see p. 27.) This giving is in addition to the billions donated by individuals directly to nonprofits and through donor-advised funds. The continued health impacts of the coronavirus and the accompanying economic crisis, combined with the resurgent movement for racial justice, impacted philanthropy so that rather than waning, the pace of COVID-19 giving continued as the year went on.

\section{Who gave?}

Corporations accounted for 44 percent of COVID-19 funding in 2020. This is a decrease from the first half of the year, when corporate foundations and corporate giving programs accounted for 66 percent of funding dollars. This decline is to be expected, as corporations are typically among the first to publicly respond with pledges of support in the immediate aftermath of a disaster or crisis. As the coronavirus pandemic continued-and even worsened-in the second half of the year, other donors, especially high-net-worth individuals, stepped up to provide additional support.

Corporate giving, totaling $\$ 9.4$ billion, includes a mix of cash donations and in-kind support with a fair-market value. The largest corporate gift was a $\$ 400$ million pledge from Wells Fargo “in processing fees to help small businesses impacted by the ongoing coronavirus (COVID-19) pandemic keep their doors open, retain employees, and rebuild." The pledge also aimed to help nonprofits and Blackowned businesses, committing an initial \$28 million to community development finance institutions (CDFIs) supporting AfricanAmerican-owned small businesses. 


\section{Funding by donor type}

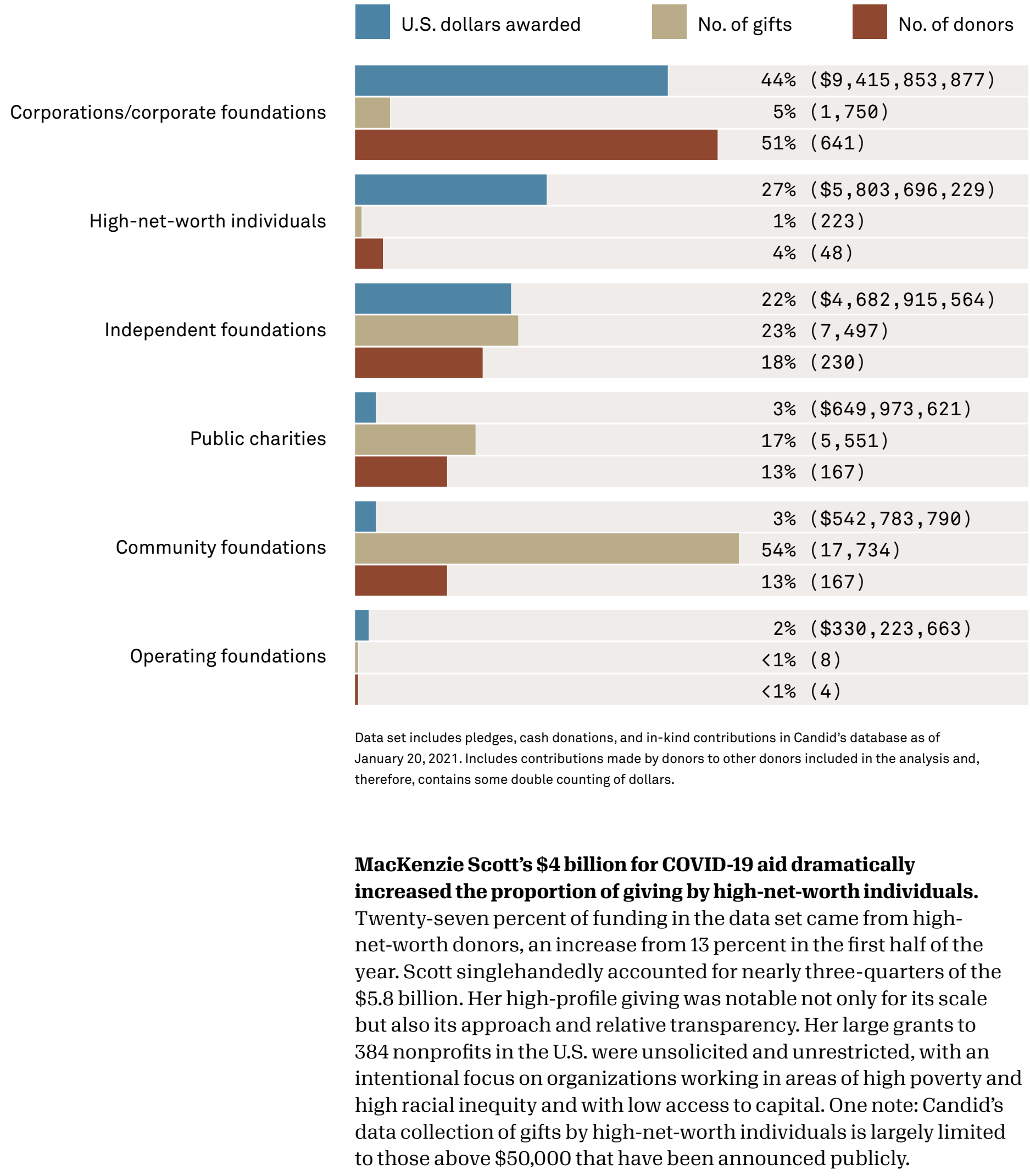




\section{Top corporate donors by total funding}

Funding from independent foundations more than doubled to $\$ 4.7$ billion.

\begin{tabular}{lllrr}
\multicolumn{1}{l}{ Name } & Location & U.S. dollars awarded & No. of gifts \\
\hline 1 & Google.org & CA & $\$ 1,157,750,000$ & 17 \\
2 & ByteDance & China & $436,840,000$ & 10 \\
3 & Wells Fargo \& Company & CA & $400,000,000$ & 1 \\
& Contributions Program & & $275,300,000$ & 3 \\
4 & MasterCard Incorporated & NY & & \\
& Contributions Program & CA & $256,366,996$ & 106 \\
\hline 5 & StartSmall LLC & Brazil & $239,826,923$ & 1 \\
6 & Itau Unibanco Holding S.A. & CA & $220,000,000$ & 4 \\
7 & Cisco Systems, Inc. Corporate Giving & & $210,000,000$ & 2 \\
& Program & CA & $197,912,028$ & 1 \\
\hline 8 & Visa Foundation & Morocco & $175,000,000$ & 1 \\
9 & Royal Holding Al Mada & MN &
\end{tabular}

Data set includes pledges, cash donations, and in-kind contributions in Candid's database as of January 20, 2021.

\section{Funding from independent foundations more than doubled,} from $\$ 1.7$ billion in the first half of the year to $\$ 4.7$ billion. The Bill \& Melinda Gates Foundation continued to be the top donor, increasing its support for the global response to the pandemic. In December 2020, the foundation made an additional \$250 million pledge (on top of its earlier commitments, which totaled more than $\$ 1$ billion) to accelerate the development and equitable distribution of COVID-19 tests, treatments, and vaccines. The Rockefeller Foundation pledged $\$ 1$ billion over the next three years for a more inclusive, green recovery from the coronavirus pandemic. This commitment focuses on scaling distributed renewable energy across developing countries as well as strengthening public health systems and ensuring more equitable access to COVID-19 tests, vaccines, and data.

\section{Top independent foundations by total funding}

\begin{tabular}{|rlrrr|}
\hline Name & Location & U.S. dollars awarded & No. of gifts \\
\hline 1 & Bill \& Melinda Gates Foundation & WA & $\$ 1,327,529,040$ & 398 \\
\hline 2 & The Rockefeller Foundation & NY & $1,111,490,484$ & 86 \\
\hline 3 & The Andrew W. Mellon Foundation & NY & $215,510,000$ & 11 \\
\hline 4 & Open Society Foundations & NY & $200,000,000$ & 2 \\
\hline 5 & Bloomberg Philanthropies, Inc. & NY & $166,300,000$ & 7 \\
\hline 6 & Ford Foundation & NY & $141,464,495$ & 191 \\
\hline 7 & Lilly Endowment Inc. & IN & $134,625,000$ & 18 \\
\hline 8 & The Robert Wood Johnson Foundation & NJ & $119,593,314$ & 230 \\
\hline 9 & Minderoo Foundation Trust & Australia & $100,537,600$ & 1 \\
\hline 10 & Michael \& Susan Dell Foundation & TX & $100,000,000$ & 2 \\
\hline
\end{tabular}




\section{$54 \%$}

of all gifts came from

community foundations.
Community foundations awarded the most grants. More than half of all gifts (54 percent) came from community foundations. As was true during the first half of the year, community foundations tended to award smaller grants, but more of them. The median award size for community foundations was $\$ 10,000$, compared with $\$ 250,000$ for corporate donors. Still, community foundations continued to play a vital role-creating COVID-19 funds, partnering and coordinating with local governments and organizations, and providing much-needed support to nonprofits on the frontlines of their communities.

Data collection efforts largely focused on the U.S., based on publicly available sources in English, including press releases, websites, membership reports, and surveys as well as funders reporting disbursements directly to Candid. Still, the data set represented philanthropy from 40 countries and special administrative regions (Hong Kong and Macau). U.S. donors made up 77 percent of funding dollars. Funding from China totaled more than $\$ 1.4$ billion, and funding from the United Kingdom was more than $\$ 600$ million. Funding went to recipients in 100 countries.

Funding in the data set loosely correlates with the severity of the pandemic's reported impact on specific countries. As of January 22, 2021, the highest number of confirmed COVID-19 cases have occurred in the U.S., India, and Brazil. The U.S., Brazil, and India have the highest COVID-19-related deaths. Among the 20 countries currently most affected by COVID-19, the United Kingdom, Czech Republic, and Italy are seeing the most deaths per 100,000 population.

\section{Top donor countries by total funding}

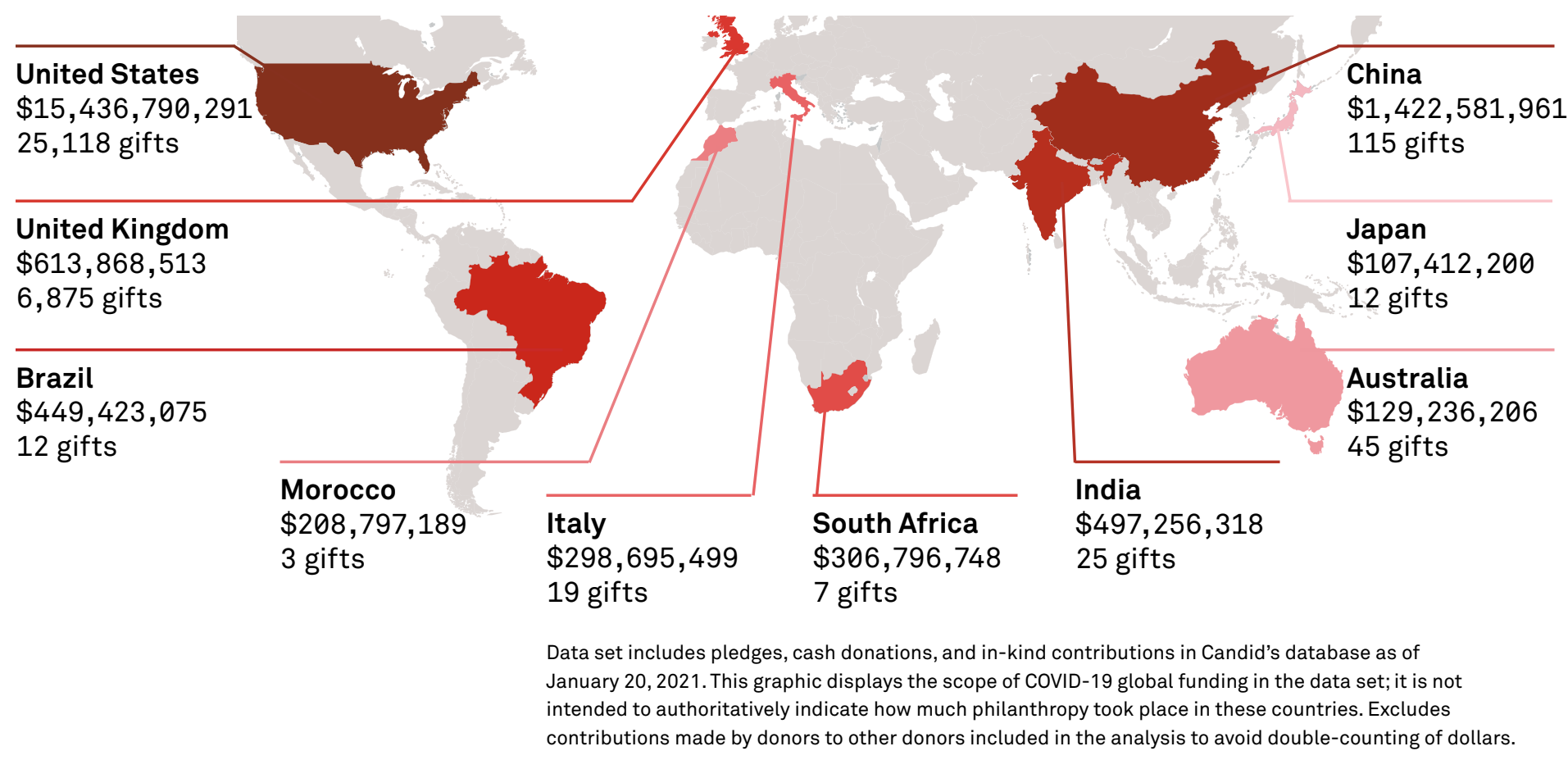




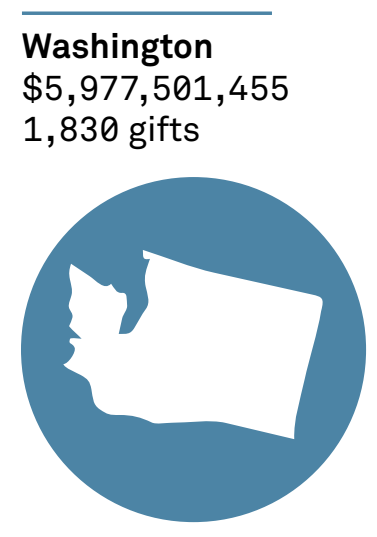

\section{California \\ $\$ 3,409,909,340$ \\ 5,710 gifts}

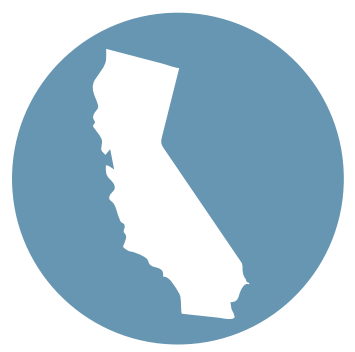

\section{New York}

$\$ 3,294,253,627$

1,437 gifts

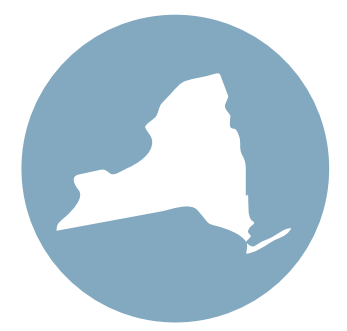

\section{Minnesota}

$\$ 348,621,302$

684 gifts

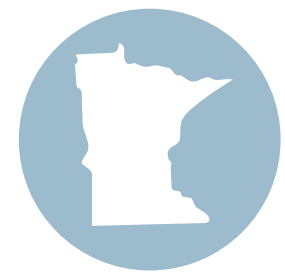

New Jersey

$\$ 294,625,584$ 1,233 gifts

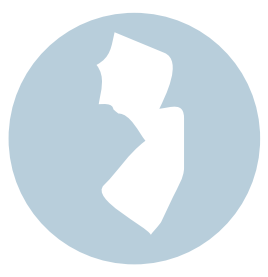

Data set includes pledges, cash donations, and in-kind contributions in Candid's database as of January 20, 2021. Includes giving by high-net-worth individuals. Excludes contributions made by donors to other donors included in the analysis to avoid double-counting of dollars.

Communities banded together to form more than 1,000 COVID-19 response funds. The majority of response funds that Candid identified were based in the U.S., representing every state as well as the District of Columbia, Puerto Rico, and the U.S. Virgin Islands. There were likely many more funds created around the world. Funds in the U.S. were often created by community foundations and/or United Ways to support regional communities. Although Candid did not comprehensively track dollars raised and distributed by all funds, the Lilly Family School of Philanthropy found that, as of June 30, 2020, COVID-19 funds created by community foundations and/or United Ways in the U.S. had raised more than $\$ 1$ billion and distributed at least $\$ 589$ million to financially vulnerable individuals and nonprofits.

A variety of funds were created to support those disproportionately affected by the pandemic. For example, Justice for Migrant Women raised \$3.4 million to help keep farmworker families safe from COVID-19. The Restaurant Workers' Community Foundation raised nearly $\$ 6.8$ million to support individual restaurant workers. Some funds addressed the challenges of school closures and distance learning. AT\&T created the $\$ 10$ million Distance Learning and Family Connections Fund to support parents, students, and teachers with athome learning. The United Negro College Fund created a campaign to raise funds for historically Black colleges and universities (HBCUs) and their students.

The Center for Disaster Philanthropy's COVID-19 Response Fund has awarded a total of $\$ 21.8$ million to 137 grantees as of late January 2021. These figures include several grants made in collaboration with the CDP Midwest Early Recovery Fund and the CDP Global Recovery Fund. $\overline{\mathrm{CDP}}$ awarded nine rounds of grants from the Fund to support domestic 
Center for Disaster

Philanthropy's COVID-19

Response Fund has

awarded a total of

\$21.8 million

to 137 grantees as of late

January 2021. and international organizations addressing the response to and recovery from the effects of the COVID-19 pandemic worldwide.

Three Fund grantees are profiled in this report: HIAS, a refugee protection organization operating in several countries worldwide; Culture Aid, a local food security nonprofit in New Orleans, Louisiana; and the National Domestic Workers Alliance, a U.S.-based nonprofit supporting the rights of domestic workers.

Gifts through donor-advised funds and \#Giving Tuesday increased in 2020. Although we cannot link this growth directly to COVID-19 giving, it is reasonable to surmise that the pandemic inspired at least part of it.

Fidelity Charitable donors recommended 2 million grants totaling $\$ 9.1$ billion to 170,000 charities in 2020, a 24 percent increase from 2019. Most donations (63 percent) allowed nonprofits to choose how to address their most urgent and immediate needs.

Schwab Charitable donors supported nearly 100,000 charities through 830,000 grants totaling $\$ 3.7$ billion in 2020 . These amounts reflect an increase of 35 percent in dollars and 39 percent in the number of grants compared to 2019. Donors recommended grants to 13 percent more charities, and 74 percent supported at least one new charity in addition to organizations they had supported in the past. Some 60 percent of grants went to organizations within a donor's own state. The top charities Schwab Charitable donors supported in 2020 included Feeding America, Doctors Without Borders, Salvation Army, Planned Parenthood, and Campus Crusade for Christ.

Vanguard Charitable donors awarded $\$ 1.8$ billion in grants, a 22 percent increase from 2019. Of the $\$ 1.8$ billion, grants totaling $\$ 92$ million were explicitly designated as “COVID-19” in the donors' purpose selection. Designations for COVID-19 dropped off at midyear. This pattern follows that of other disaster giving: donors use the purpose selection primarily to expedite grants at the outset of a disaster, because Vanguard Charitable prioritizes review on grants with that purpose.

\#GivingTuesday raised nearly $\$ 2.5$ billion in December 2020, up 25 percent from 2019. An estimated 34.8 million people participated, a 29 percent increase from 2019. \#GivingTuesday promotes not just monetary gifts but also acts of generosity, encouraging individuals to volunteer or to help neighbors in need. On May 5, 2020, \#GivingTuesdayNow, a global campaign created in direct response to the COVID-19 pandemic, raised another \$503 million. 


\section{HIAS}

HIAS received a $\$ 200,000$ grant from the Center for Disaster Philanthropy to mitigate COVID-19related risks among women, girls, $L G B T Q$, and other marginalized groups to ensure gender-based violence $(G B V)$ survivors can access response services. The grant will also help service providers' preparedness to support survivors in future waves of the pandemic.

HIAS began in 1881 as the Hebrew Immigrant Aid Society to assist Jews fleeing pogroms in Russia and Eastern Europe in finding refuge in the U.S. The organization describes its history and mission in this way, "Because we have helped more than 4.5 million people escape persecution, HIAS is uniquely qualified to address the modern refugee situation, which has mushroomed into a global humanitarian crisis. We understand better than anyone that hatred, bigotry, and xenophobia must be expressly prohibited in domestic and international law and that the right of persecuted people to seek and enjoy refugee status must be maintained. And because the right to refuge is a universal human right, HIAS is now dedicated to providing welcome, safety, and freedom to refugees of all faiths and ethnicities from all over the world."

HIAS' work has since expanded to people from other countries, religions, and backgrounds. Jessica Reese, HIAS associate vice president, strategy and development, said, "We began to take our resettlement and integration expertise that we had with the Jewish population and apply it to other populations. Today, the majority of the people we serve are not Jewish. In the early 2000s, we expanded to Kenya and Ecuador as our first international offices. We saw the need to serve people as they navigated the resettlement process and build safe communities for refugees in the countries of first refuge where the majority now remain indefinitely."

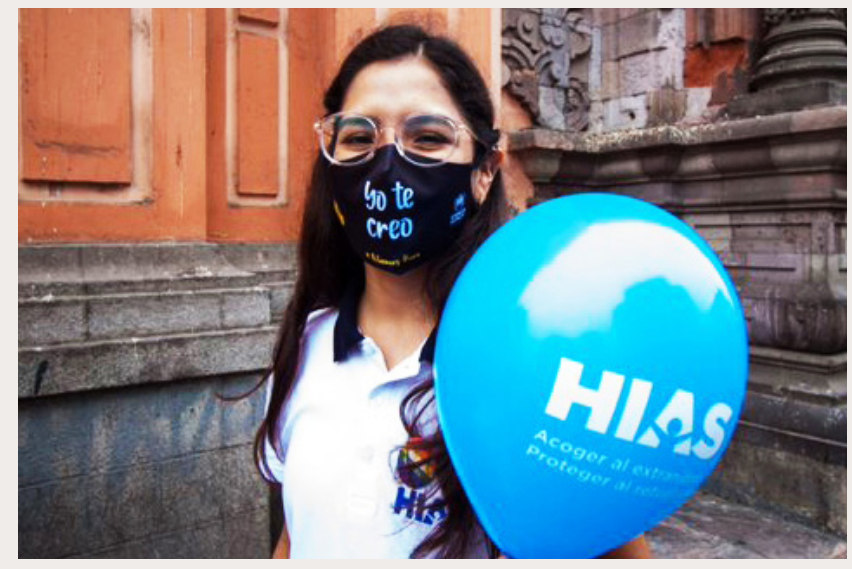

Photo of staff from HIAS' gender-based violence (GBV) team in Lima, Peru, commemorating the 16 Days of Activism Against GBV. Photo courtesy of HIAS

HIAS now supports refugees and asylum seekers in 16 countries globally and across 20 American cities, including along the southern U.S. border. They are one of only a handful of international organizations working in Venezuela. Their work includes international and domestic policy advocacy, humanitarian assistance, and domestic legal support and resettlement. HIAS' international programs are based in four areas of work: legal assistance, livelihoods, psychosocial support, and prevention and response to genderbased violence.

Heidi Lehmann works for HIAS as the senior director, technical excellence. She said, "We are always aware of how underlying gender inequality is going to be impacted by a crisis. In the situation of COVID-19 we saw right away that it was exacerbating different kinds of violence, and so we focused on getting support to survivors. Because of our multidisciplinary programming, we are able to meet a variety of survivor needs."

CDP's grant provided support for HIAS' work in Costa Rica and Peru. In both countries, many of 
"People who were vulnerable

at the start of COVID-19

are now even more

vulnerable; the needs are

just as urgent today."

the women that HIAS serves work in the informal economy. Women and girls suffered more than men and boys from the economic impact of the pandemic's lockdowns in both countries. The responses in each country were shaped to meet the specific needs presented by women and girls.

In Costa Rica, HIAS noted 11 case of femicide in 2020 and 4,302 cases entered in Domestic Violence Courts in 2020. HIAS worked handin-hand with domestic violence survivors to help them leave their abusive relationships. Their efforts included the provision of legal information, assistance in obtaining basic ID, and overall survivor accompaniment. Lehman said, "We helped them get everything they need, walking with them every step of the way."

In northern Costa Rica HIAS deployed a specialized staff member with training on gender-based violence to get information to survivors who were coming into the country from Nicaragua as quickly as possible. Lehman said, "We recognized how many women had experienced violence on the way to Costa Rica. Besides homes, borders are one of the most dangerous places for women and girls.”

In Peru, knowing that there was limited mobility because of lockdowns, HIAS used mobile protection units to get as close to survivors as possible. They would go out into the communities and explain, "We can help you get from service point A to service point B," Lehman said. "We provided a lot of help and counseling. But the reality is that a lot of survivors cannot leave. So, we provided counseling and safety planning to keep them safe, even in the homes where violence was happening. Because of CDP's funding, alternative and safe short-term shelter became an option.”

Lehman explained that they also recognized early on the likelihood of a disproportionate impact on adolescent girls, so they established funding to run programs specifically for them. This funding enabled creation of small peer groups among the young women where they could provide support to each other. She added, "In those groups, we would have semi-structured discussions about relationships and around risks, particularly [related] to trafficking, child early marriage, and forced unions. Our goal was to try to reduce their risks of these issues. When it's all said and done, and COVID-19 is in the rearview mirror, we will be shocked by the amount of trafficking that went on. In Peru especially, our program was really part of addressing the impact this was having on adolescent girls. Girls are seen as disposable and can be a source of revenue for a family."

Both Reese and Lehman pointed out that CDP's flexibility in allowing HIAS to identify the needs, the funding gaps, and the best solutions based on the individual countries and their experiences was critical to their success. And as one of the first funders to make significant grants, CDP's support helped increase awareness of genderbased violence among other donors. Reese said, "We raised \$3.4 million in direct COVID-19 funding from individuals, private foundations, etc. CDP's name carries a lot of weight and it allowed us to not just leverage funds, but it also encouraged donors to take the pandemic seriously."

She added, "Between Heidi and I, we have been doing this for decades. This is a crisis like no other. We have humanitarian workers who are burned out and yet are still providing services. We have responded for months, but the acute crisis isn't over. People who were vulnerable at the start of COVID-19 are now even more vulnerable; the needs are just as urgent today." 


\section{Who received funding?}

The majority of funding dollars continued to lack details about where funding is directed. About 63 percent of funding ( $\$ 13.5$ billion) went to "unknown" recipients, where funders announced a donation but did not specify its recipients, or to "multiple” recipients, where recipients were named without specifying how much funding each received. We therefore continue to have limited information about most donations and where they are directed.

The analysis that follows focuses on funding directed to specified recipients.

\begin{tabular}{|c|c|c|c|c|}
\hline & Recipient organization & Location & U.S. dollars awarded & No. of gifts \\
\hline 1 & Start Small LLC & $\mathrm{CA}$ & $\$ 1,000,000,000$ & 1 \\
\hline 2 & Gavi Alliance & Switzerland & $415,000,000$ & 6 \\
\hline 3 & COVID-19 Therapeutics Accelerator & WA & $198,000,000$ & 9 \\
\hline 4 & Feeding America & IL & $126,660,100$ & 37 \\
\hline 5 & $\begin{array}{l}\text { Easter Seals (national office } \\
\text { and affiliates) }\end{array}$ & United States & $126,000,000$ & 1 \\
\hline 6 & South African Future Trust & South Africa & $111,263,880$ & 2 \\
\hline 7 & The Skoll Foundation & $\mathrm{CA}$ & $100,000,000$ & 1 \\
\hline 8 & $\begin{array}{l}\text { Prime Minister's Citizen Assistance } \\
\text { and Relief in Emergency Situations } \\
\text { Fund }\end{array}$ & India & $91,388,110$ & 6 \\
\hline 9 & UK Community Foundations & $\begin{array}{l}\text { United } \\
\text { Kingdom }\end{array}$ & $89,192,124$ & 44 \\
\hline 10 & Solidarity Response Fund & South Africa & $83,447,910$ & 2 \\
\hline
\end{tabular}

\section{Top recipients by U.S. state}

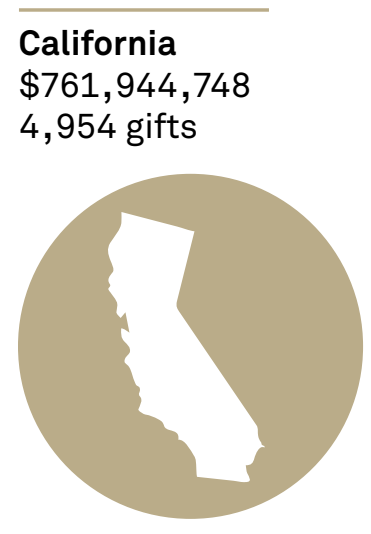

New York
$\$ 430,508,180$
986 gifts

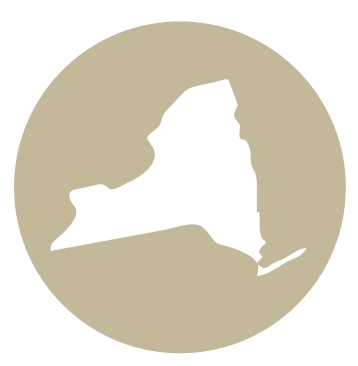

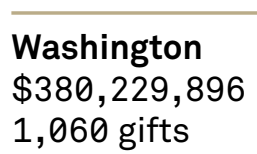

1,060 gifts

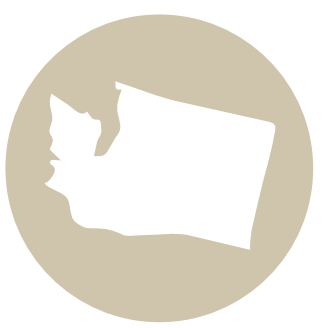

\section{Illinois \\ $\$ 344,061,983$ \\ 340 gifts}

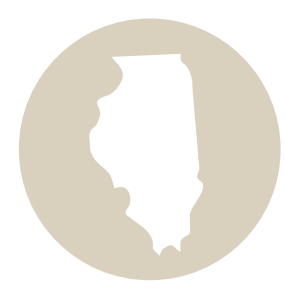

Texas

$\$ 301,476,386$ 702 gifts

Data set includes pledges, cash donations, and in-kind contributions in Candid's database as of January 20, 2021. Includes giving by high-net-worth individuals. Excludes awards to unknown recipients. Also excludes contributions made by donors to other donors included in the analysis to avoid double-counting of dollars. 
Issue focus of recipient organizations

\begin{tabular}{|c|c|c|c|c|}
\hline Issue & U.S. dollars awarded & $\%$ & No. of gifts & $\%$ \\
\hline Human services & $1,889,191,760$ & 28 & 10,553 & 33 \\
\hline Health & $1,707,201,790$ & 26 & 3,400 & 11 \\
\hline Education & $1,314,809,498$ & 20 & 2,261 & 7 \\
\hline $\begin{array}{l}\text { Philanthropy and nonprofit } \\
\text { management }\end{array}$ & $772,569,884$ & 12 & 1,135 & 4 \\
\hline Public safety & $730,324,590$ & 11 & 1,248 & 4 \\
\hline $\begin{array}{l}\text { Community and economic } \\
\text { development }\end{array}$ & $624,605,984$ & 9 & 2,806 & 9 \\
\hline \multicolumn{5}{|c|}{$\begin{array}{l}\text { Data set includes pledges, cash donations, and in-kind contributions in Candid's database as of } \\
\text { January } 20,2021 \text {. Organizations may address multiple issue areas (e.g., health and public safety) and } \mathrm{m} \\
\text { therefore, be counted in more than one category. Includes giving by high-net-worth individuals. } \\
\text { Excludes awards to unknown recipients. Also excludes contributions made by donors to other donors } \\
\text { included in the analysis to avoid double-counting of dollars. }\end{array}$} \\
\hline
\end{tabular}

The majority of funding to unknown or multiple recipients came from corporations ( $\$ 8.1$ billion). Since corporations are not required to report their grantmaking (unlike U.S. foundations which, by law, must disclose some minimal information), unless they voluntarily disclose more details, we are unlikely to learn how these dollars were ultimately allocated. (See CDP's recommendation for greater data transparency on p. 26.)

Human service organizations received the largest share of funding Human service organizations received

\section{$28 \%$}

(the largest share of funding), among awards to specified recipients.
(28 percent), among awards to specified recipients. This is a change from funding in the first half of 2020, where health and public safety organizations received the most support. Human service organizations, which have been on the front lines of the pandemic, include food banks, United Ways, YMCAs, and YWCAs. Feeding America, a U.S.-focused hunger relief organization, received a number of large gifts, including $\$ 100$ million from Jeff Bezos. Another organization that received significant support was India's Prime Minister's Citizen Assistance and Relief in Emergency Situations (PM CARES) Fund, administered by the Indian government to provide relief during the pandemic and for other disasters.

Health organizations ranked second, accounting for 26 percent of dollars. Top health organizations included Gavi, the Vaccine Alliance, an international organization created to improve access to vaccines in the world's poorest countries, and the COVID-19 Therapeutics Accelerator, a philanthropic collaboration to help speed up the development of COVID-19 therapeutics. Easterseals (the national office combined with its affiliates) emerged in the top recipient list thanks to MacKenzie Scott's \$162 million award. The organization offers services and advocacy for people with disabilities. 
Of the $\$ 1.7$ billion to health-focused organizations, less than 2 percent of dollars (\$29 million) but 25 percent of gifts (863) went to mental health organizations. The proportion of funding was unchanged since our last report. StartSmall LLC was notable as a supporter of mental health organizations, with nine grants totaling \$3.5 million. Awards included \$1.3 million to the Jed Foundation, enabling mental health experts to provide virtual consultations and funding trainings, and \$1.1 million to the Trevor Project, an organization focused on suicide prevention among LGBTQ youth.

\section{What did funding look like?}

Thanks to MacKenzie Scott, funding for unrestricted or flexible support dramatically increased to

\section{$39 \%$}

from $3 \%$ in the first half of the year.
Funding for unrestricted or flexible support dramatically increased:

39 percent of dollars and 21 percent of gifts to specified recipients were described as unrestricted or flexible. By comparison, we documented only 3 percent of dollars for general support in the first half of the year. However, MacKenzie Scott's very large, unrestricted grants accounted for much of this shift. Excluding her grantmaking, flexible support reflected only 9 percent of all dollars awarded to named recipientsstill an increase, but a more modest one.

In a 2020 survey of 236 foundations, the Center for Effective Philanthropy (CEP) found that 75 percent were providing a higher proportion of unrestricted grant dollars compared with before the pandemic. The increased priority on unrestricted funding was evident in the data, based on the increase in the second half of the year.

Funders had other means of making funding more flexible that is not necessarily reflected in the data. A survey by the Global Philanthropy Project of 26 foundations supporting LGBTQI issues reported that 85 percent of funders had extended grant timelines or reporting requirements, and 70 percent had shifted projects grants to unrestricted grants. These actions would not be captured in the data set, which largely consists of new awards.

\section{Nine percent of COVID-19 dollars addressed policy and systems} change. The twin pandemics of the coronavirus and systemic racism brought attention to the role philanthropy should play in engaging in policy and systems change. But a relatively small proportion of COVID-19 funding to specified recipients could be identified for this purpose. Among the largest awards in this category were grants focused on equitable access to COVID-19 diagnostics, therapies, and vaccines.

In interviews with 41 foundation leaders, CEP found that 80 percent raised policy and systems change as important issues, especially around advocacy and organizing. Leaders viewed advocacy as an important strategy in addressing the policies and underlying 
systems that create disparities, but only 17 percent reported that their foundations began supporting grantee advocacy as a result of the pandemic.

Similarly, proportionately few dollars in the data set (1 percent) had a specific focus on advocacy and grassroots organizing. One rare example of such funding was a $\$ 3$ million award from the John D. and Catherine T. MacArthur Foundation to the Democracy Frontlines Fund, a donor collaborative launched in 2020 to provide multiyear support for community organizing efforts by 10 African-American-led nonprofits. The gift was part of a larger effort by the foundation to support communities impacted by COVID-19 and systemic racism.

\section{Nearly a quarter of funding dollars designated for specific recipients} went to BIPOC communities. Among all funding in the data set to specified recipients (including global funding), 23 percent of dollars was explicitly designated for communities of color or went to organizations serving communities of color. When excluding highnet-worth donors and looking only at institutional philanthropy (corporations, foundations, and public charities-whose giving was the focus of the last report), the percentage directed to communities of color dropped to 13 percent. Still, this is an increase from the 5 percent we reported in the first report.

The racial justice movement in the United States in 2020 had an impact on COVID-19 funding for BIPOC communities. Of U.S. COVID-19 philanthropy to specified recipients, 35 percent of dollars was designated for communities of color. High-net-worth donors in the data set designated a higher proportion of their funding for BIPOC

\section{Proportion of funding explicitly designated for BIPOC communites in the U.S., per donor type}

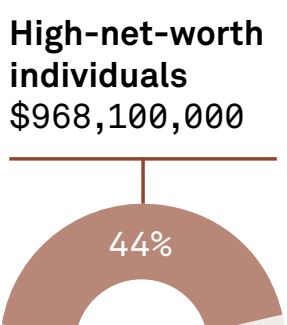

$\$ 2.2 \mathrm{~B}$

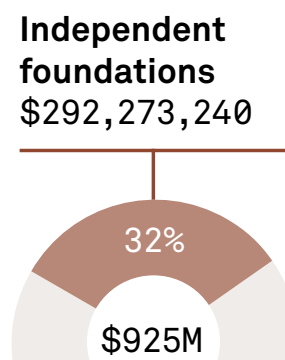

$\$ 925 \mathrm{M}$
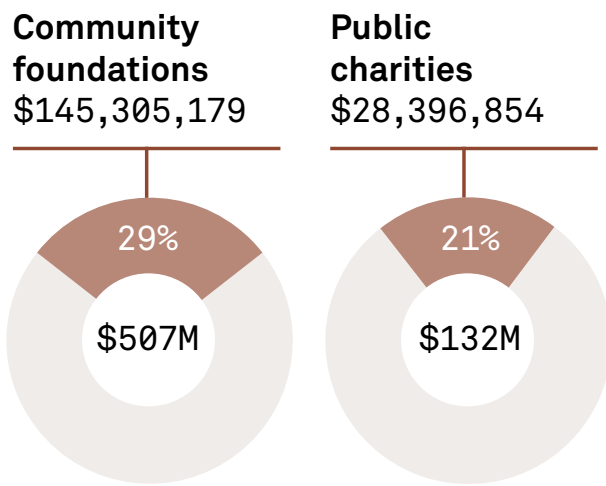

\$132M

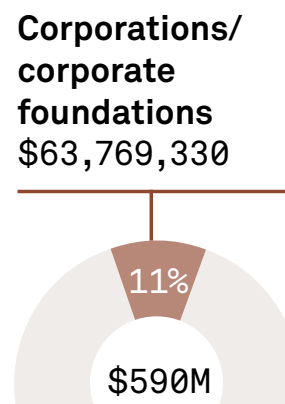

All donor types $\$ 1,497,944,603$

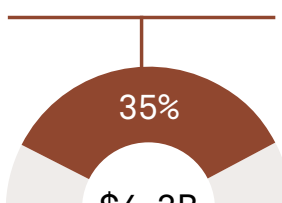

$\$ 4.3 \mathrm{~B}$

Total dollars are to specified recipients in the U.S. Data set includes pledges, cash donations, and in-kind contributions in Candid's database as of January 20, 2021. Excludes awards to unknown recipients. Also excludes contributions made by donors to other donors included in the analysis to avoid double-counting of dollars. "All donor types" includes gifts from operating foundations. 
Children receive toys at an Alianza Contigo event in Chicago, Illinois. Thousands of families received fresh food and essential goods including bedding, baby supplies, and toys. Photo courtesy of Good360
Of U.S. COVID-19 philanthropy to specified recipients,

\section{$35 \%$}

of dollars was designated for communities of color.

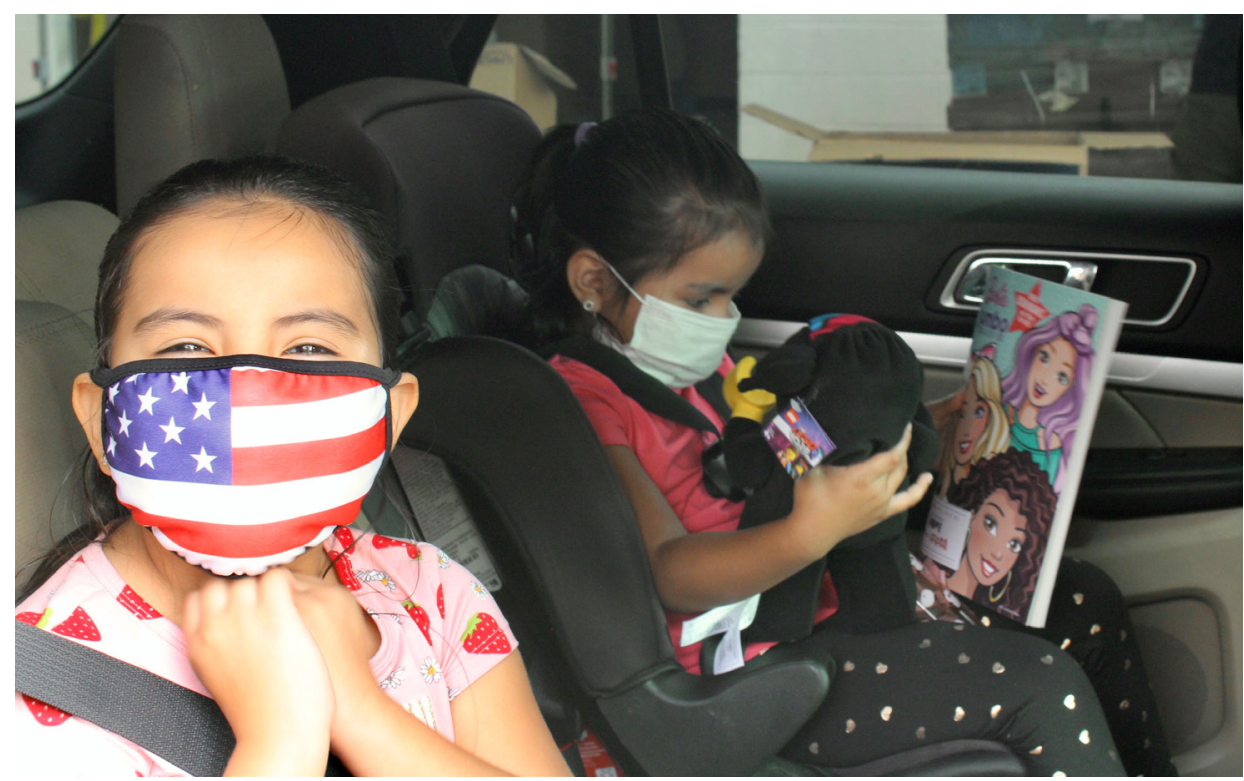

communities (44 percent). This was almost entirely due to MacKenzie Scott's grantmaking. There were only two high-net-worth donors in the data set who awarded grants designated for BIPOC communities: Colin Kaepernick awarded one grant, and MacKenzie Scott awarded the remainder. Only 11 percent of corporate funding to named recipients was designated for BIPOC communities.

It is worth noting that some of the increase in BIPOC funding since our last report may be due to improvements in data collection. Candid became more intentional about looking for and coding data concerning funding for BIPOC communities, as donors also became more explicit about addressing BIPOC communities in their COVID-19 grantmaking.

Funding in this category included grants to organizations whose work and missions are grounded in specific BIPOC communities. For example, the Community Foundation of Greater Memphis announced a \$40 million endowment to LeMoyne-Owen College, a historically Black college in Memphis, Tennessee, recognizing the challenges students faced because of the pandemic and the initiatives the college had instituted to meet their needs.

Other awards were for specific projects to increase equity: PayPal announced the creation of a $\$ 10$ million fund for Black-owned businesses impacted by COVID-19. The fund provides support to business owners to cover expenses related to stabilizing and reopening their businesses. The fund is managed in partnership with the Association for Enterprise Opportunity, a national nonprofit expanding economic opportunity for Black entrepreneurs through its Tapestry Project. 
Funding directed explicitly for people with disabilities increased from $1 \%$ in the first half of the year to $8 \%$.
Eight percent of funding was directed explicitly for people with disabilities, an increase from the 1 percent reported in the first report. The Ford Foundation awarded \$2 million in general support to the Disability Rights Education and Defense Fund. The organization advocates for persons with disabilities around the world and builds diverse movements, ensuring inclusive development agendas to achieve equal rights and opportunity.

Funding included people with psychosocial disabilities. The Australiabased Stan Perron Charitable Foundation awarded more than $\$ 600,000$ to Youth Focus, a mental health provider in Western Australia, whose demand for services grew more than 24 percent due to the pandemic.

Four percent of COVID-19 dollars was specifically directed for women and girls, or organizations serving women and girls-a marginal increase from 3 percent in the first report. The Spanx by Sara Blakely Foundation donated $\$ 5$ million to GlobalGiving in support of female entrepreneurs in the U.S. Also, Alwaleed Philanthropies announced a \$2.3 million contribution to the Islamic World Educational, Scientific and Cultural Organization in support of efforts to empower women and young entrepreneurs in Africa and support the production of hygiene products and protective equipment in the battle against the coronavirus.

Two percent of funding continued to be directed to immigrants and refugees, or organizations addressing their needs. Salesforce donated \$9 million to the Oakland Unified School District in California to help middle school students and educators get through the coronavirus pandemic, with a focus on unaccompanied immigrant youth, refugees, and asylum seekers. Seven grants totaling more than $\$ 960,000$ came from the Seattle Foundation to the Scholarship Junkies COVID-19 Relief Fund for undocumented individuals in Washington State.

Two percent of funding continued to specify older adults. UnitedHealth donated \$5 million to AARP to address social isolation and food insecurity among seniors in the U.S. The San Diego Foundation awarded $\$ 150,000$ to Meals on Wheels of Greater San Diego through its COVID-19 Community Response Fund to support increased demand for assistance to quarantined seniors. 


\section{Culture Aid NOLA}

Culture Aid NOLA received a $\$ 90,000$ grant from the Center for Disaster Philanthropy (CDP) to provide no-barrier, free food distribution and information dissemination to New Orleans residents most affected by COVID-19 and most at risk of economic collapse from widespread job loss and lack of public or private safety nets.

Executive director Erica Chomsky-Adelson is a $12+$ year disaster response veteran. When COVID-19 led to closures in New Orleans on March 13, 2020, she was working as a program coordinator at Tulane University. She immediately knew that there was going to be a high need for food. She says, "I got on the phone with friends and said, 'What are we going to do? We know we're going to go do something?” The answer was "feed people."

Building on her extensive network and relationships with nonprofits and other service providers, Chomsky-Adelson got to work. As restaurants began shutting down and cleaning out their kitchens, she and her friends took that food. She recalls, "We went to Liberty's Kitchen [a nonprofit kitchen that trains at-risk youth] and cooked 500 meals. We were not prepared. I remember turning people away the first night and feeling very nauseous. That's when we knew we couldn't fail. The next week it was 750 meals.”

As connections grew, so did the volume. By the third week, they were serving 5,000 meals. The demand kept growing, so they transitioned to providing groceries instead of prepared meals, allowing people to prepare food tailored to their tastes and needs. As logistical operations expanded, Chomsky-Adelson formed Culture Aid NOLA, a coalition of several organizations, including the New Orleans Musicians Clinic, Music and Culture Coalition of New Orleans,

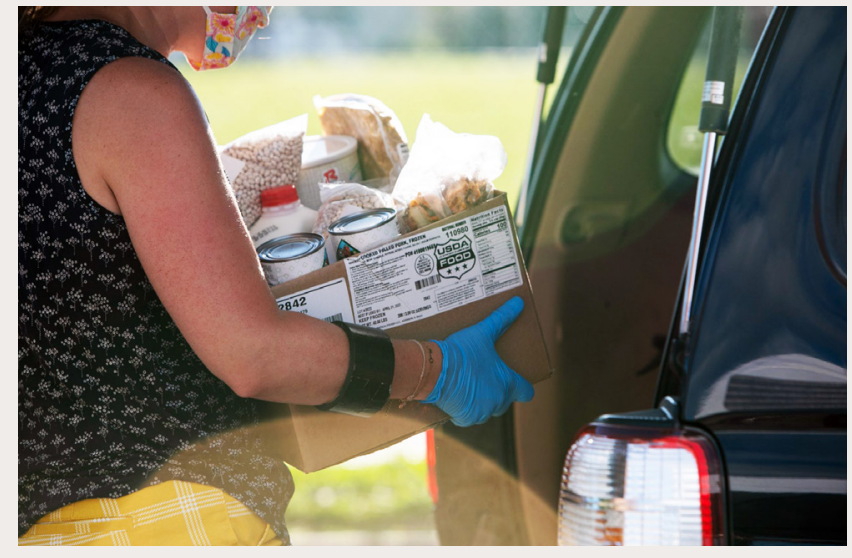

A masked volunteer loads a box of free groceries into the trunk of a car in New Orleans. Photo courtesy of Culture Aid NOLA

New Orleans Food Policy Advisory Committee, Second Harvest Food Bank, Lowernine.org, and Trinity Loaves and Fishes.

Many of the Culture Aid volunteers were hospitality workers and culture bearers. This led to the operationalization of Culture Aid as a hospitable, no-barrier, stigma-free environment. Chomsky-Adelson explains, "A lot of times when you try to access any kind of resource, you have to provide ID, proof of income, copy of a lease, copy of a utility bill, but we know that's not the best way to reach people. People who are undocumented, people who don't have those documents and particularly during coronavirus, people who are ashamed, don't want to put themselves into the position of proving to a stranger that they have need."

Culture Aid has two main modes to manage its massive food distribution program. From March 13 to December 31, 2020, alone, Culture Aid NOLA served 95,000 people by distributing 500,000 pounds of food. It partnered at a hyperlocal level with community organizations and organizers, such as neighborhoods, community 


\begin{abstract}
"People who are
undocumented, people who

don't have those documents

and particularly during

coronavirus, people who are

ashamed, don't want to put

themselves into the position

of proving to a stranger that

they have need."
\end{abstract}

groups, Social Aid and Pleasure Clubs, and Mardi Gras Krewes, by providing grocery boxes they could deliver directly to their members.

"The one lesson we have not yet learned in disaster response is that there are existing and highly resilient support networks already in communities. We have a tendency to say 'everything is broken right now' after a disaster and we tend to view a community as a blank slate. But in marginalized communities, there are hundreds of support groups," said ChomskyAdelson. "We work with local community partners to enable them to support their own communities. For example, we work with a longtime community leader, super important to her community and leader of a well-known Social Aid and Pleasure Club. She is often overlooked because they don't have the formal networks, formalized relationships, 501(c)(3) status, etc. We're able to go in and say, 'You know your people, you know what they need, you know where they live, here is some food, go and take care of them."

The second method is weekly distributions in hard-hit neighborhoods. As cars arrive on site, they are greeted warmly by bilingual volunteers who say something like, "Hello, thank you for coming tonight. Are you here for your groceries? We have some lovely cabbages and carrots tonight. Can I interest you in a fresh mask?”
During the food distribution, Culture Aid also pays local DJs and musicians to play. This practice employs musicians, brings joy to people in line, and provides a soundtrack for the hardworking volunteers.

Chomsky-Adelson says that the atmosphere contributes to the comfort level of those picking up their groceries. “The only question we ask on site is 'How many people are you trying to feed?' There is no paperwork. We are setting the expectation that people are deserving of and welcome to the food. There is no stigma. There's a lot of shame around the inability to feed your family. We try to show people hospitality, dignity, grace. In fact, we have a banned words list'need, food bank, desperate,' etc.”

CDP's grant provided significant capacitybuilding support for Culture Aid. ChomskyAdelson was still working at Tulane University and running Culture Aid (she left the University in October 2020 to focus on continuing to expand the organization), but the funding enabled the organization to hire a few part-time staff members to help manage activities. The timing of the grant coincided with the pending expiration of a crucial USDA waiver. She says, "We spent a significant portion of the CDP grant on local food from local suppliers and managed to place a standing order with SPROUT NOLA, a local farmers' collective. The grant came at a make it or break it point for us. It kept the operation moving.”

She added, "Having the support of a trusted funder like CDP let us leverage that grant to attract other funders. It gave us a solid foundation to build a long-term commitment to the community and a promise that we wouldn't leave people behind. The understanding from CDP of the importance of general operational support was crucial. It was overnight capacity building for us and our partners.” 


\section{What is the impact of the pandemic on the U.S. nonprofit sector?}

The U.S. nonprofit sector lost nearly

\section{0,000}

jobs since the crisis began.
The U.S. nonprofit sector lost nearly 930,000 jobs by December 2020 , according to a conservative estimate from the Johns Hopkins Center for Civil Society Studies. This is a 7 percent decline from February 2020. Nearly 37 percent of workers at arts and entertainment organizations lost jobs. Education nonprofits lost 15 percent of their workforce, about 300,000 jobs. The Center estimates that it could take 1.5 years (17.8 months) to return to the pre-COVID-19 level of employment.

In 2020, Candid published a series of analyses examining the potential economic impact of the pandemic on the U.S. nonprofit sector.

Before the pandemic, the U.S. nonprofit sector showed resiliency. A look at historical data shows that the sector, as a whole, saw significant growth over the last two decades (see top chart on p. 23). The sector's net assets increased by more than $\$ 1$ trillion from 1998 to 2017. In addition, the sector demonstrated an aggregate financial surplus every year. Even during periods of financial crisis (in 2002, 2003, and 2009), it successfully managed to increase expenses (suggesting growth in activities, programs, and services), without exceeding revenue.

This view of the sector in aggregate, however, masks the countless individual nonprofits that struggled during this time. The circumstances of large nonprofits (like billion-dollar hospitals or universities) tend to obscure what happens to the thousands of very small nonprofits that make up the sector.

\section{Most nonprofits are positioned to survive a short recession,} but a longer one could be devastating (see second chart on p. 23). The median U.S. nonprofit has about six months of cash, which means that if a nonprofit's expenses stayed the same but its revenue went down to zero, it could continue its current activities for another six months. This figure differs significantly according to the issue areas in which nonprofits work. Public safety, disaster preparedness, and relief organizations have a median 17 months of cash, whereas mental health and crisis intervention organizations have a median of 3 months of cash. 


\section{Aggregate nonprofit revenue vs expenses (in trillions)}

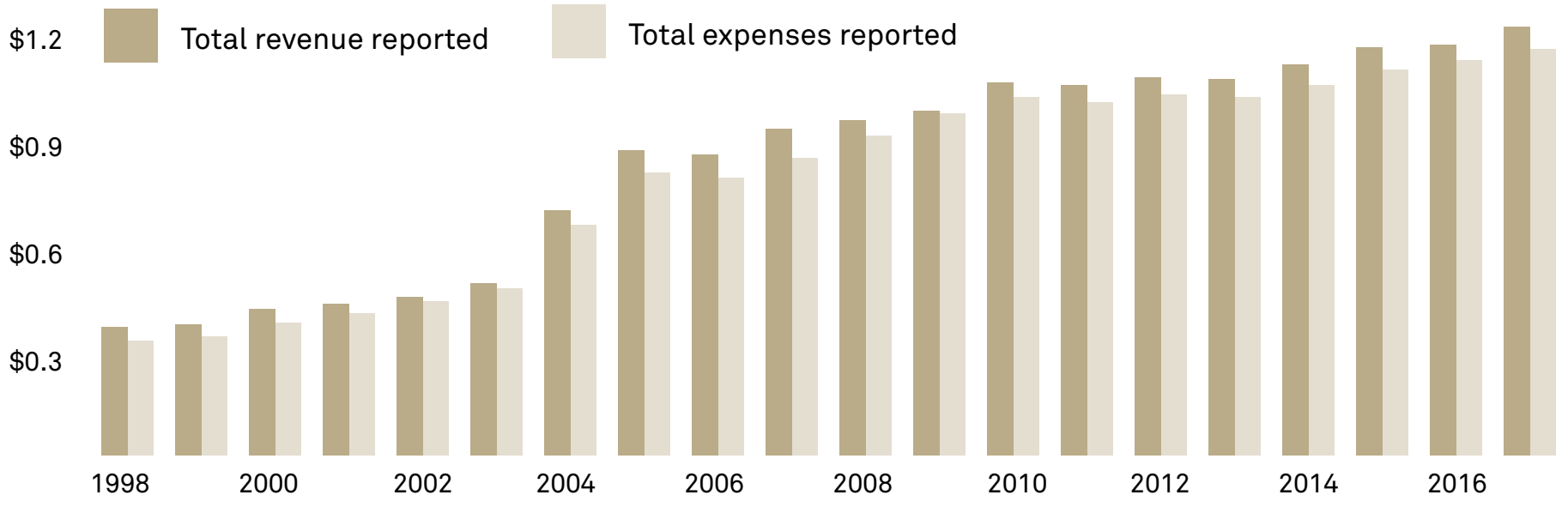

\section{Number of organizations by months of cash}

70,000

60,000

50,000

About half of nonprofits have

40,000

30,000

20,000

10,000

\section{six or fewer months of cash}

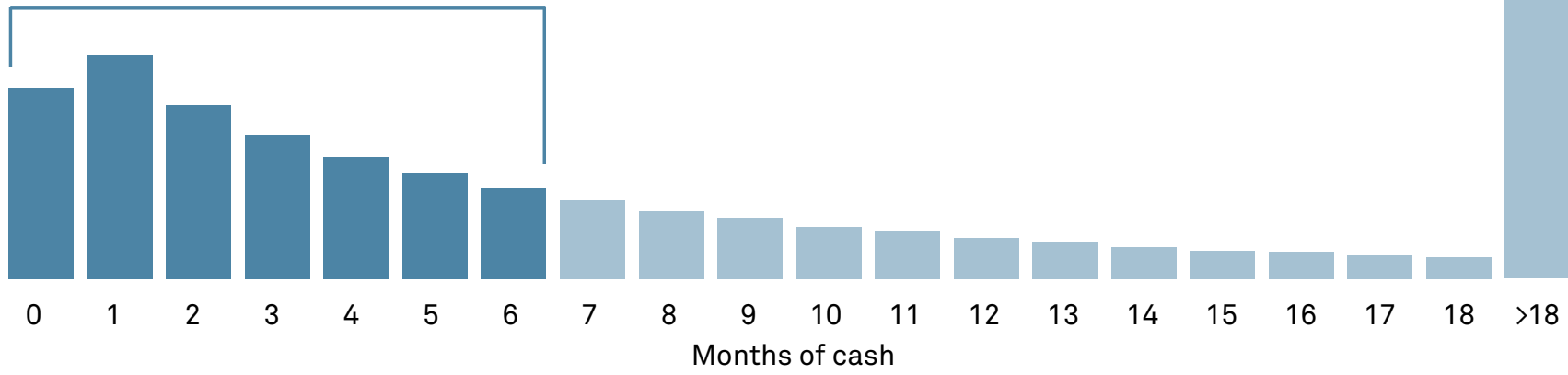

How many U.S. nonprofits will shut their doors because of the pandemic? No one can say for sure, but Candid ran 20 different scenarios to understand the range of possible outcomes. The study found that in the absence of a crisis, a baseline of 12,042 nonprofits (4 percent) could close. Across various "realistic" scenarios of how the crisis could play out, a median of roughly 34,472 nonprofits (11 percent) could go out of business. This means that about 22,000 additional nonprofits (7 percent) could close due to the COVID-19 pandemic. In the worst-case scenario, the sector could lose as many as 119,517 (38 percent) organizations.

A state-by-state analysis found that the District of Columbia may lose the most nonprofits per person because of the crisis, followed by Vermont and North Dakota. By sheer numbers, California and New York are poised to lose the most nonprofits, 2,688 and 1,829 organizations, respectively. 


\section{National Domestic Workers Alliance}

National Domestic Workers Alliance (NDWA) received a $\$ 125,000$ grant from the Center for Disaster Philanthropy to help start up a \$30 million direct cash assistance fund for domestic workers in critical need and to support those workers with information, other resources, and personal protective equipment so they can continue to work safely. Additionally, funds allowed NDWA to advocate on workers'behalffor local, state, and federal policy changes to improve their work conditions and allow them access to available support resources.

Founded in 2007, NDWA works "for respect, recognition, and inclusion in labor protections" with and on behalf of the more than 2.5 million domestic workers in the U.S.

Domestic workers are nannies, housekeepers, and home care workers who work with the elderly or people with disabilities to help them live more independently. The majority are women of color-Black, Latina, Asian, and Indigenous. Almost all are women; some are undocumented. They are paid low wages, have little to no benefits, and there is little to no pathway for enforcement of their rights, given their intentional exclusion from federal labor laws protecting workers. Discrimination is ever-present, as is potential wage theft. Because their workplaces are private homes, these jobs can easily conceal abuse, especially for those in live-in situations.

They are also usually one paycheck away from a crisis, so COVID-19 has become a life-or-death situation for many in the industry. Jennifer Dillon, communications director for NDWA, said, “They care for people. Care doesn't take a day off. Everything that happened across the U.S. was multiplied for domestic workers. As things were shutting down, they had to make a choice if they would go to their clients' houses or not get paid.”

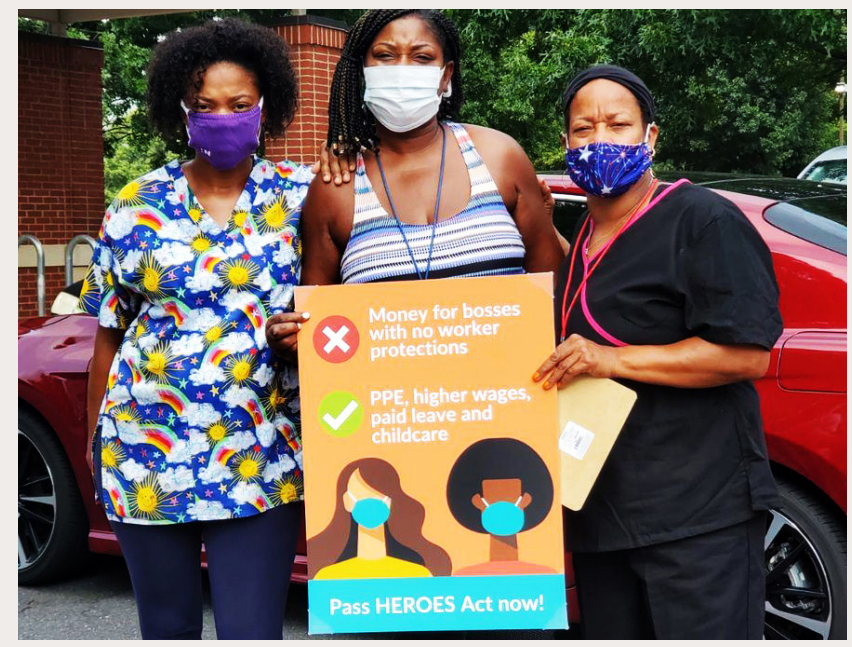

NDWA We Dream in Black members in North Carolina urge Senators Burr and Tillis to pass the HEROES act to provide essential domestic workers with access to PPE and other support. Photo courtesy of Gina Esquivel, NDWA

For many domestic workers, not getting paid means they cannot afford groceries or pay their rent. There is no social safety net for domestic workers, and many were ineligible for the financial assistance provided by the government because of their documentation status.

Domestic workers are often undervalued, in part because the majority are women of color and immigrant women. They have been historically left behind through economic policies, according to Dillon. NDWA, she says, "works to be able to improve conditions of domestic workers but also to build power for domestic workers through connecting them, educating them, and organizing them.”

Kaylyn Kvochak, NDWA's deputy development director, said, "Our bread and butter is the organizing piece. We strive to be led in everything we do by the workforce-in our policy advocacy, culture and narrative change and in our product and innovations strategies. We look at how to build power for domestic workers and for women of color more broadly." 
"Response is usually

charitable, but it doesn't look

at the needs further along or

the inequities that created

the conditions."

Dillon added, "The reason that we have multiple strands of work that we do is because we're trying to change the care sector but also the lives of immigrant women and women of color. We have to have layers of strategies that are interconnected to make major wins for their lives.”

Kvochak explained that situations varied for domestic workers when the lockdowns started and as the pandemic has continued. During the initial lockdowns, some home care workers continued to work because their clients were vulnerable and depended upon them. But they had to try to figure out how to shoulder the additional burden. For example, some employers asked care givers to take private transportation, which put pressure on already tight household budgets. Many workers had their own kids out of school, which meant they needed to secure child care.

"Nannies and housekeepers saw their incomes evaporate overnight as we were asked to limit exposure to people outside of the home," Kvochak said. "We saw people talking about food and housing insecurity. This could have been predicted but now the value of care and the precarity of care work came into sharp relief into ways that they hadn't been thought about before. All of a sudden, everyone had care issues and were thinking about the ramifications of what that meant. We asked ourselves, 'How do we help our workforce navigate the immediate crisis but also use the moment to accelerate the conversation around expanding the safety net to protect all workers.”

A weekly Spanish-language survey was conducted, each one drawing a sample of domestic workers from NDWA's digital network of more than 230,000 workers, allowing NDWA to track the changing needs of workers throughout the pandemic and providing complementary economic data for workers who are often underrepresented in more formal indicators. These internal surveys showed that more than 70 percent of domestic workers experienced a significant loss of income in the early months of the pandemic.

Kvochak noted that CDP's grant, which NDWA received in the early stages of the pandemic, helped them leverage different strategies and respond in real time. For example, the grant funded an intense communications and narrative campaign to get domestic workers' stories front and center in the news media. They also used the funding to distribute PPE to keep their workforce safe. They created resources such as COVID-19-ready training for home care workers to keep themselves and their clients as safe as possible. And it helped support the extra support staffing needed to distribute over $\$ 30$ million raised for cash assistance to impacted workers.

The policy work CDP funded was also critical. “Response is usually charitable, but it doesn't look at the needs further along or the inequities that created the conditions," said Dillon. "We wanted to explore how do we create something different-not just address the short-term piece. CDP's funding allowed us to fund immediate needs and long-term policy advocacy." 


\section{CDP recommendations for philanthropy}

The data tells us a story of numbers and issues. The case studies tell us the stories of the people on the ground and the organizations working to serve their needs. But this is only part of the narrative.

As funders, we need to ask ourselves, “Now what?” What is our responsibility to create change, now and in the future? Even if everyone were vaccinated tomorrow, the pandemic is leaving behind broken systems and fractured communities, families, and individuals. CDP has a number of recommendations for grantmakers to consider through 2021 and beyond to ensure equitable recovery from COVID-19.

\section{Report your data to Candid and ensure that grant descriptions} are clear and explicit. The lack of details in this report could be reduced if funders were more proactive in describing their grants and sharing information. Good data is important to identify gaps in funding, critical needs, at-risk populations, and geography. Creating better data can help funders make more informed and strategic giving decisions, leading to higher-impact grants.

This pandemic will have long-term impacts and cannot be solved by pre-2020 contribution amounts. 
migrants, refugees, immigrants-are also at risk during other disasters. Although this report highlights an increased focus on grants for BIPOC-led and BIPOC-serving organizations, these grants were awarded in a time of heightened focus on police violence, systemic racism, and racial discrimination. The pandemic laid bare systemic discrimination in many American and international systems and structures. These issues need continual support and funding to address the root causes of these inequitable situations. In addition to financial resources, funders should also support advocacy and community engagement as a vital component of addressing systemic inequities.

5. Expand your reach and your dollars. COVID-19 has confirmed for us that all funders are disaster funders. Think about new areas and ways to make grants outside of traditional grantmaking circles. If you normally fund youth, ensure you are identifying specific funding opportunities for organizations serving BIPOC youth or those serving young girls. International grantmaking to help low-tomoderate income countries is also critical. Many of these countries continue to report shortages of testing, which hide the true nature of the virus in their communities. They also suffer from a lack of medical equipment, personal protective equipment (PPE), and medical personnel. It is not enough to solve this crisis in wealthier countries-we need a global solution.

\section{Methodology}

Data for this COVID-19 funding analysis came from publicly available sources in English, including press releases, websites, membership reports, and surveys as well as funders reporting disbursements directly to Candid. The data set includes a mix of pledges, authorized grants, and paid grants. The level of detail for each award varies dramatically. Some contain rich descriptions for each recipient, whereas others provide only an overall total without specifying the recipient(s).

The aggregate findings presented in this report reflect data in Candid's database as of January 20, 2021. Data processed in 2021 still reflects giving from 2020, due to the time required to collect and load the data. The giving recorded in this analysis is substantial but not comprehensive, and there are undoubtedly more donors and awards that are not reflected in the data set. We will not know the full scope of COVID-19 philanthropy, specifically in the U.S., until we see foundations' 2020
IRS Forms 990-PF and their allocation of grants. Candid is, however, continuing to add grants to its database every day, which will undoubtedly include additional 2020 data.

For the latest funding data, please visit Candid's coronavirus special issue web page. And to see how coronavirus funding compares with other funding for disasters and humanitarian crises, visit the Measuring the State of Disaster Philanthropy website and funding map, a collaboration between the Center for Disaster Philanthropy and Candid.

Please share your data with us! If you are a funder and would like to see your grantmaking included in the funding map and future COVID-19 analyses, please email egrants@candid.org for more information. 
